\title{
Sobre teatro italiano na rede
}

\section{Maria João Almeida}
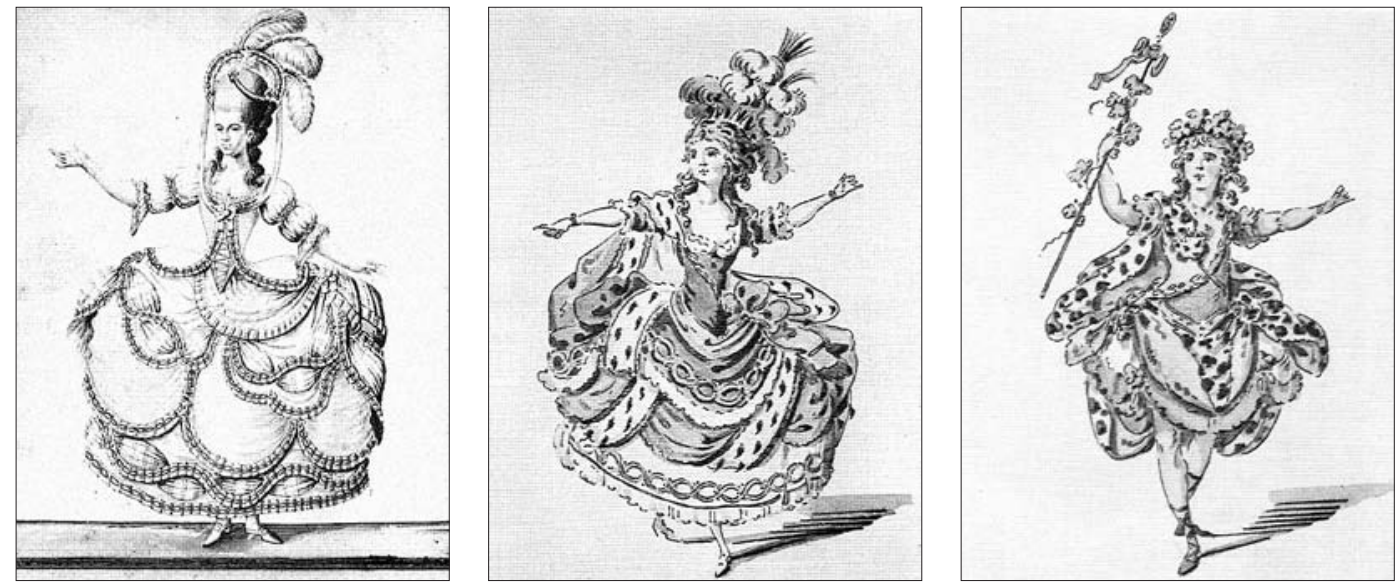

As imensas potencialidades (teóricas e práticas) do encontro entre artes do espectáculo e novas tecnologias têm vindo a ser exploradas de modo consistente em Itália nos últimos anos. Para se ter uma imagem aproximada desta realidade, sugere-se a consulta dos artigos de Oliviero Ponte di Pino, Alcuni appunti sulla scena italiana di internet, e de Irene Giorgi, Teatro e Internet: informazione, diffusione e formazione dello spettatore in Italia, incluidos no arquivo informático de ateatro, webzine de cultura teatral (http://ateatro.it) da responsabilidade de Oliviero Ponte di Pino e Anna Maria Monteverdi. Ali se encontrará muita informação actualizada (mas inevitavelmente incompleta face à dinâmica imparável da rede) sobre outros sítios de interesse para investigadores profissionais, outros utentes de referência e o grande público, motivado ou não. Limitome, por isso, a centrar os apontamentos de divulgação que se seguem sobre três sítios bem concebidos e melhor conseguidos.

\section{Mantova Capitale Europea dello Spettacolo:} http://www.capitalespettacolo.it

0 grande atractivo deste espaço de suporte virtual criado pela Fondazione Mantova Capitale Europea dello Spettacolo reside no facto de facultar o acesso a um arquivo informático - o Herla - relativo à actividade espectacular promovida ou patrocinada pelos Gonzaga nos anos compreendidos entre 1480 e 1630, o tempo áureo da casa senhorial de Mântua. De acordo com as notas de apresentação do Projecto Herla (acessiveis a partir da home page), teatro, música e festas constituem o seu âmbito de investigação, entendendo-se a espectacularidade em sentido lato porque, além de "teatro de corte", commedia dell'arte, "melodrama" e "teatro hebraico", as informações coligidas reportam-se também a "banquetes nupciais", "torneios", "entradas triunfais", etc. De tipologia muito variada, os documentos a inventariar encontramnúmero de arquivos/bibliotecas de cidades europeias, entre as quais figura Lisboa (fornece-se lista das instituições visitadas até à data).

Actualizado três vezes por ano, o sítio proporciona ao utilizador a vantagem de poder inteirar-se do "estado dos trabalhos", divulgando, por um lado, o elenco de eventos e figuras em relação aos quais já foi rastreada informação e, por outro, o período cronológico e a área temática contemplados pela investigação em curso. Há a lamentar, no entanto, que o Herla, concebido para tratar material documental que constitui "entre um quarto e um quinto de toda a documentação mundial sobre os espectáculos do Renascimento e do barroco", não venha a estar disponivel on line na sua totalidade, mas apenas na sede da Fundação.

Para quem desejar conhecer o Herla e explorá-lo de modo eficaz, aconselha-se uma primeira pesquisa por "categorias", quinze no total: Attori (actores); Itinerari attori (itinerários de actores); Relazioni degli attori (relações dos actores); Allestimenti di spettacoli (montagem dos espectáculos); Apparati cerimoniali (os aparatos cerimoniais); Tipologie spettacolari (tipologia dos espectáculos); Musica (música); Danza (dança); Spettatori e cronache (espectadores e crónicas); Drammaturgia e altro materiale letterario (dramaturgia e outro material literário); Editoria (actividade editorial); Teatro ebraico se não só em instituições italianas, mas ainda em grande
Maria João Almeida

é docente da Universidade de Lisboa e investigadora do Centro de Estudos de Teatro.

Senhora em figurino polaco, segunda metade do séc. XVIII, aguarela de Giovanni Antonio Braganza (Milão, Museo Teatrale alla Scala)

Figurino da segunda metade do séc. XVIII, de L. Marini (Turim, Biblioteca Reale).

Figurino da segunda metade do séc. XVIII, de L. Marini (Turim, Biblioteca Reale). 
O Sr. Horácio um enamorado, ameaça vingar-se de Arlequim por

este ter requestado senhora dos seus afectos

Dona Lúcia.

(teatro hebraico); Accademie (academias); Ruoli teatrali e parti (papéis de teatro e partes); Iconografia spettacolare (iconografia do espectáculo).

Museo virtuale del Burattino e della Marionetta: http://www.buma.it

0 "buma", que pretende tornar-se um ponto de referência para estudiosos, gente do ofício ou simplesmente curiosos em matéria de marionetas e bonifrates, apresenta a colecção destes "actores" inanimados (até agora vedada aos olhos do grande público) pertencente às Scuole Civiche di Milano, que vem classificada como uma "das mais amplas e completas do género na Europa". Fazem parte do acervo mais de 500 marionetas e bonifrates, desde Setecentos até aos anos 40 do século passado, e ainda os respectivos acessórios, cenografias e documentação variada que integra "copioni", "canovacci" e manuscritos de companhias italianas dos últimos três séculos. Navegando no museu virtual, podemos também seguir a evolução por que passaram as máscaras da commedia dell'arte ao longo dos tempos.

Outro dos motivos de interesse do sítio são os "eventos em rede". Em Abril de 2007, estava acessivel Moda e Marionette nel 1700, uma exposição virtual sobre o vestuário do século de Goldoni em que as "manequinsmarionetas" exibiam as peças originais da época e as variantes estilísticas que se viam, então, em palco.

\section{Carlo Goldoni, Drammi per musica:}

http://www.carlogoldoni.it

No ano do tricentenário do nascimento de Goldoni, é oportuno assinalar este projecto (dirigido por Anna Laura Bellina e Luigi Tessarolo) que virá colocar na rede todos os seus textos poéticos para música. Trata-se da edição crítica a partir de testemunhos existentes na Casa di Goldoni (Veneza), consultados no original (editio princeps)
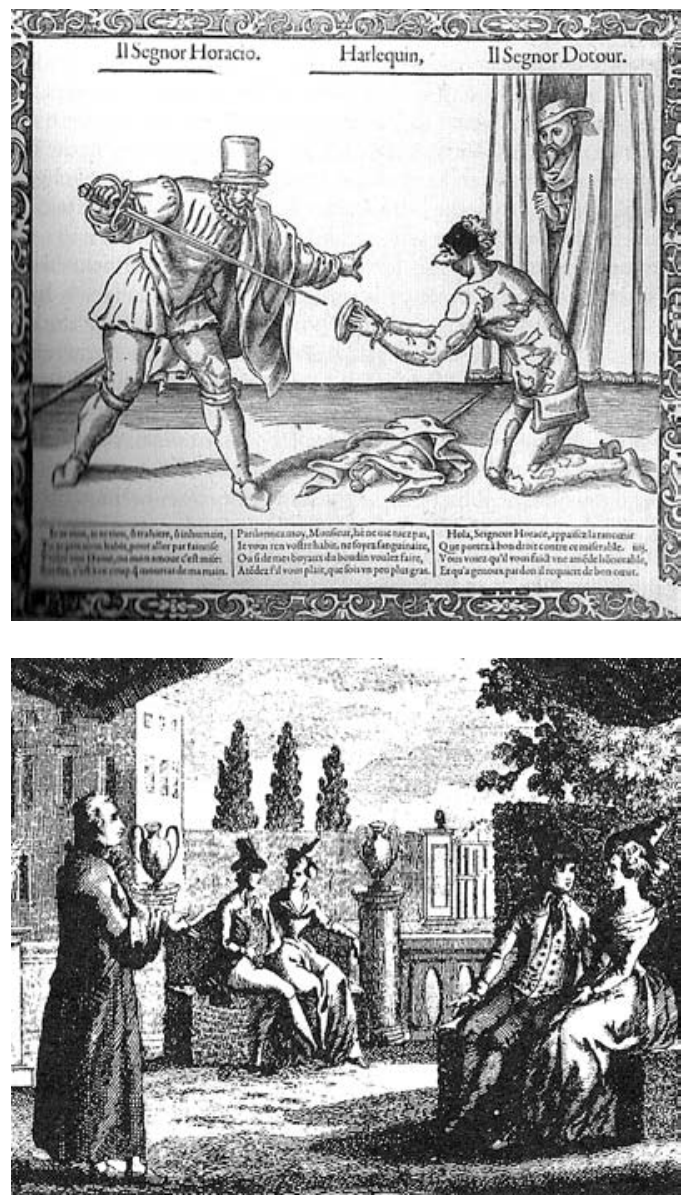

ou em reprodução, que inclui também os títulos de atribuição incerta, os pastiches (pasticci) e as reescritas (rifacimenti) feitos pelo veneziano de textos alheios. A importância e o interesse da iniciativa (financiada pelo Ateneo Patavino juntamente com o Ministero dell'Università e della Ricerca Scientifica e Tecnologica) devem ser avaliados tendo em conta que a edição informática permite aceder às redacções do autor posteriores à primeira versão de um libreto (como sucede no caso L'Arcadia in Brenta), que não constarão da futura publicação impressa pela Marsilio (Veneza) no âmbito da "edição nacional" das obras completas. Note-se bem que a edição informática precede a edição em livro e é, aparentemente, "mais" exaustiva. No espaço dedicado à apresentação do projecto, o sítio fornece uma densa e extensa "Nota aos textos" (única fonte consultada para a elaboração desta nota) e os critérios de transcrição. 